\title{
Pameran Tunggal Syakieb Sungkar: Retro Expressionism, Painting Reenactment
}

\author{
Asmudjo J. Irianto \\ iirnaga@gmail.com
}

Asmudjo J Irianto adalah seorang dosen, kurator seni rupa, dan juga pematung. Lahir di Bandung, 26 September 1962. Menyelesaikan S1 (1990) dan S2 (1999) di Fakultas Seni Rupa dan Design ITB. Pernah berpameran pada " $7^{\text {th }}$ Asian International Art of the Nothern Territory" di Darwin, Australia (1992), "International Exchange Exhibition" di Dingo Flat Farm, Tongledale and Access Gallery, Curtin University, Australia (1997), " $4^{\text {th }}$ Ceramic Biennale", Icheon, Kyonggi, Korea (2002), "Unoriginal Sin: Art in the Expired Field” (pameran tunggal), Selasar Sunaryo Art Space, Bandung (2014).

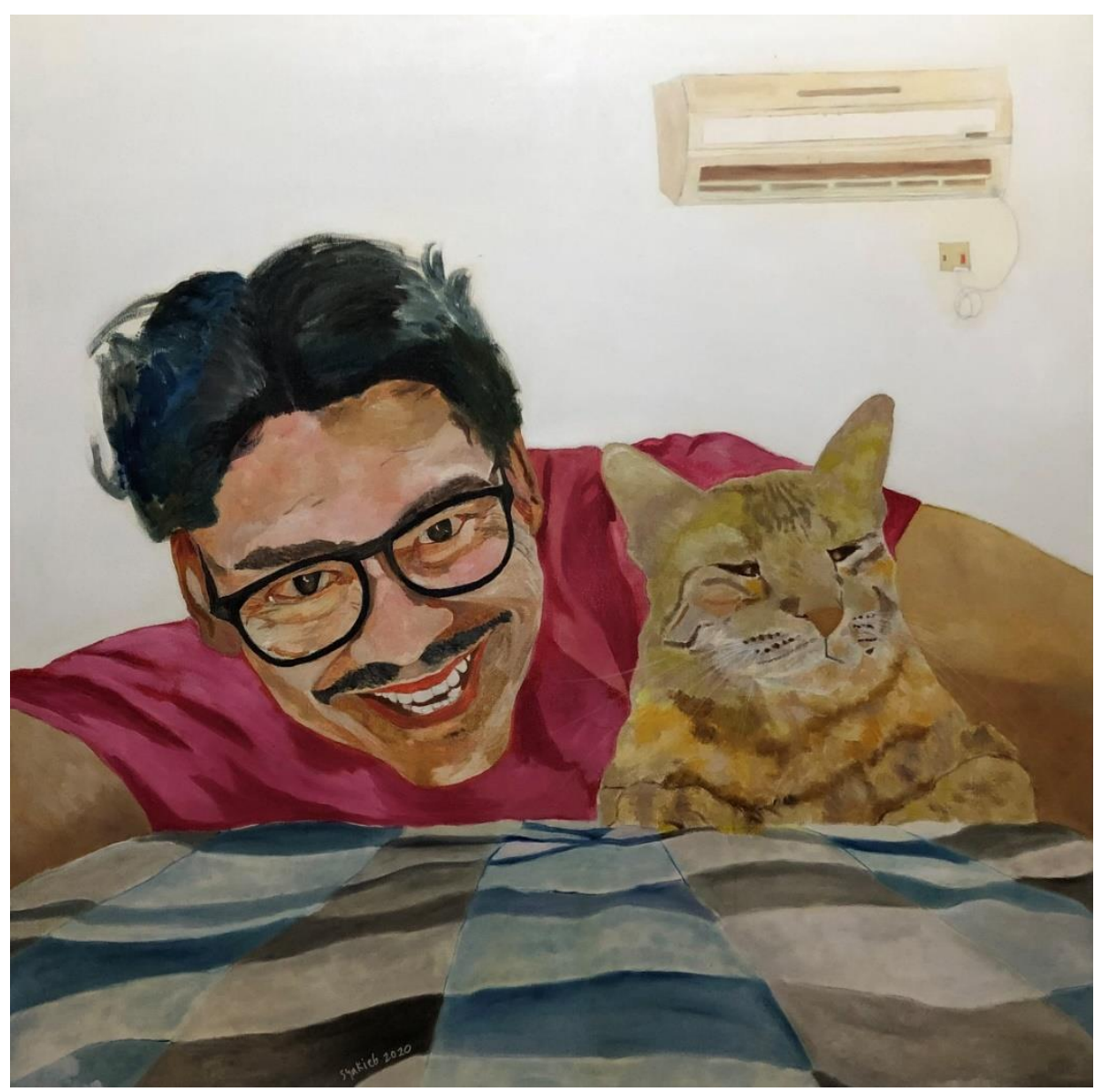

Gambar 1 - Syakieb Sungkar, "Me and Ginger”, 2020. 
Syakieb Sungkar bukan nama yang asing dalam medan seni rupa kontemporer Indonesia. Dia dikenal sebagai kolektor, juga sebagai art dealer. Sejak tahun 2006 dia memiliki blog di internet yang mengulas persoalan seni rupa, kebudayaan dan politik. Sayang — karena satu dan hal lain-blog ini tidak belanjut. Saat ini dia juga menjadi kepala editor jurnal filsafat Dekonstruksi (bermula dengan studi S-2 Syakieb di Driyakarya). Dia juga kerap menulis essay pengantar untuk pameran para pelukis Jakarta. Namun tidak banyak yang tahu bahwa Syakieb beberapa tahun belakangan ini adalah juga seorang pelukis.

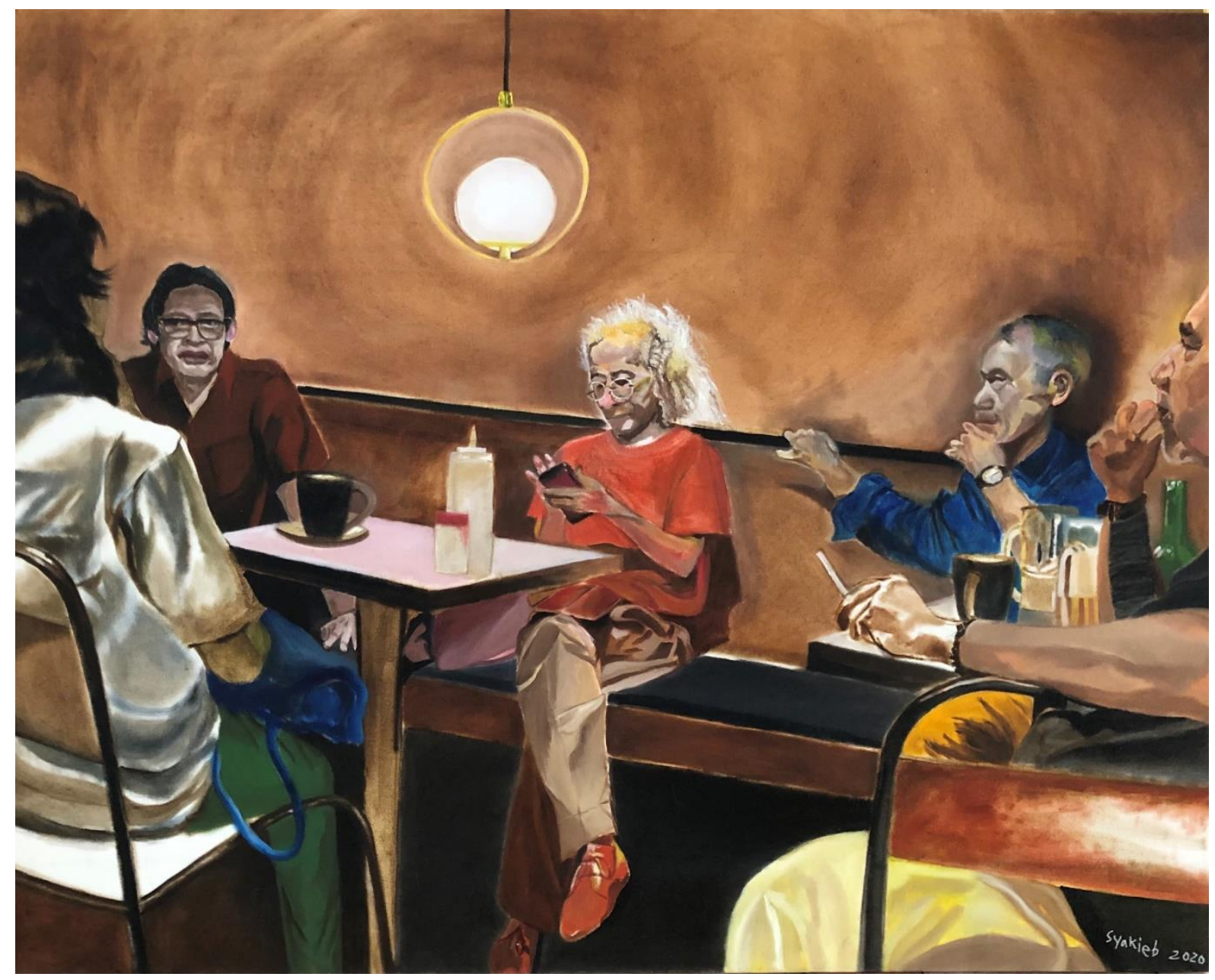

Gambar 2 - Syakieb Sungkar, "Dinner with Tony”, 2020.

Bisa jadi, Syakieb terinspirasi teman dekatnya, sastrawan Goenawan Mohamad yang saat ini juga dikenal sebagai pelukis. Pameran ini, merupakan pameran tunggal Syakieb yang pertama, 
dan juga pertama kali karya-karyanya hadir ke hadapan publik seni. Sangat jarang kolektor yang juga seniman, terutama yang berani menggelar pameran tunggal — tidak berapa lama setelah mulai melukis. Pertanyaannya, mengapa Syakieb butuh melukis? Apa yang ditawarkan oleh lukisan-lukisan Syakieb? Istimewakah lukisan Syakieb? Bagaimana posisi lukisan Syakieb dalam medan seni lukis kontemporer Indonesia? Tentu saja, seharusnya pertanyaan reflektif tersebut berlaku untuk setiap pelukis di Indonesia, tidak hanya untuk Syakieb. Namun, kehadirannya sebagai pelukis yang baru akan masuk gelanggang setidaknya memicu pertanyaan-pertanyaan tersebut.

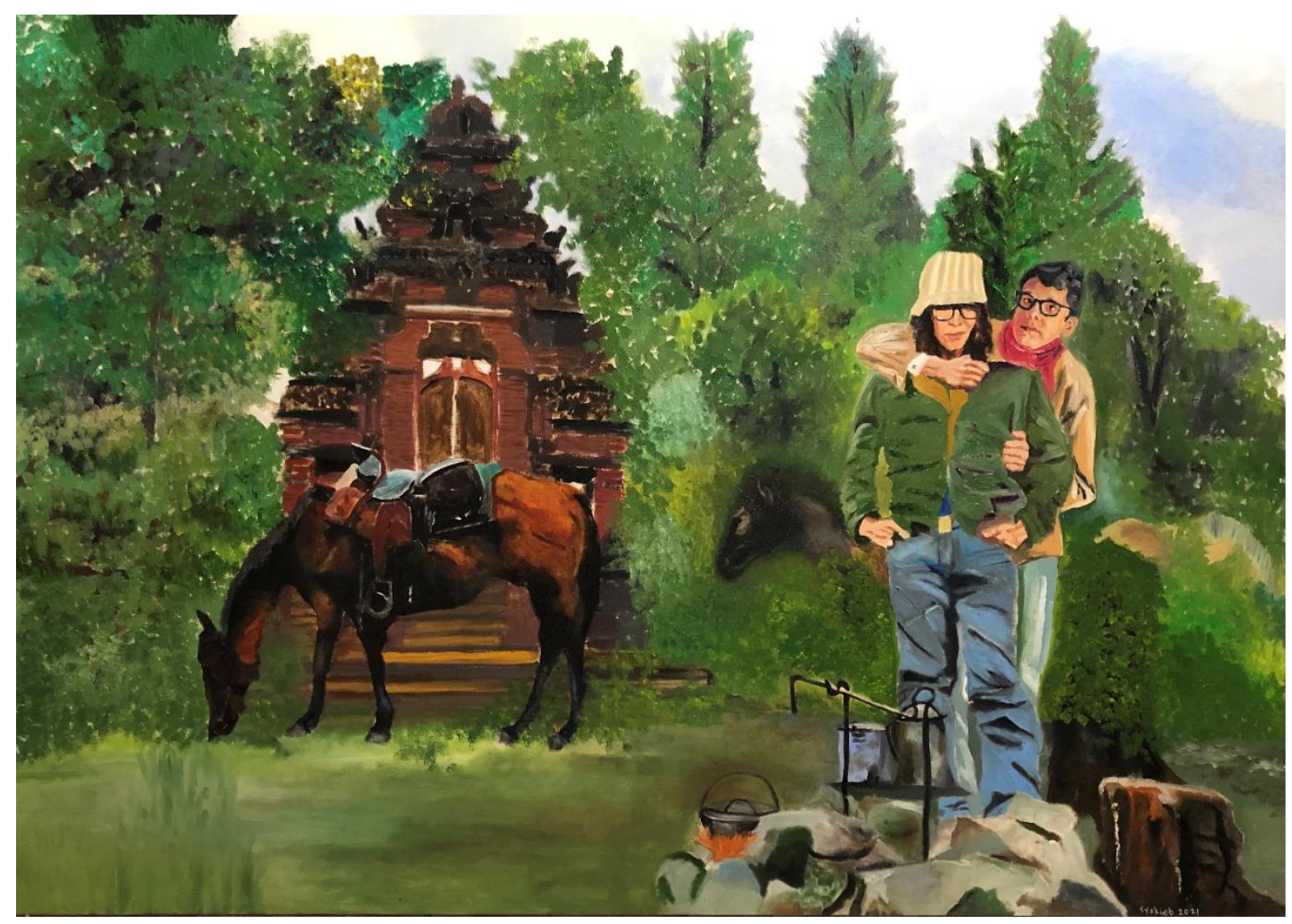

Gambar 3 - Syakieb Sungkar, "Brokeback Mountain”, 2021.

Sebagai pelukis yang mulai di usia yang sudah mature tentu bukan hal yang mudah. Syakieb tentu tidak dapat serta merta melukis dan berangkat dengan pengetahuan tacit, yaitu pengetahuan yang tumbuh dari pengalaman melukis. Untuk itu, mau tidak mau Syakieb berangkat dari pengetahuan dan pemikiran. Salah satu tempat "sekolah" Syakieb adalah medan seni rupa kontemporer Indonesia, melalui pergaulannya dengan para seniman, kolektor, kurator 
dan kritikus seni. Selain, istrinya, Anna Sungkar yang merupakan seorang Doktor seni rupa juga menjadi pendorong dan teman diskusi Syakieb sejak awal berkaitan dengan niatnya menjadi pelukis. Selain itu, melalui membaca, Syakieb memiliki pengetahuan cukup medalam mengenai teori dan wacana seni. Latar belakangnya sebagai lulusan S-2 filsafat juga menjadi modal kognisinya.

Syakieb faham bahwa seni rupa modern dan kontemporer otonom sangat mementingkan sosok seniman sebagai pengarang. Kendati estetika otonom ini mendapatkan banyak perlawanan, namun demarkasi ruang-ruang praktik seni otonom tetap terjaga, dan berkelindan dengan para antagonisnya (seni partisipatori dan kolektif seni). Dalam estetika otonom modernis, seni lukis menduduki peranan utama, apa yang disebut seni rupa modern tak lain adalah seni lukis. Kendati setelah itu, seni lukis berkali-kali dinyatakan "mati"—-karena kehadiran fotografi, seni instalasi, heppening art, performance art, new media art-namun seni lukis membuktikan dirinya dapat terus hidup dan berkembang. Daya hidup seni lukis, terjadi justru karena dalam seni rupa kontemporer, seni lukis adalah salah satu medium di antara berbagai medium lain. Hal ini menyelamatkan seni lukis, karena hilang bebannya sebagai medium yang menjadi paradigma seni rupa. Barry Schwabsky menjelaskan perbedaan tersebut, painting as art dan painting as an art, yang pertama menempatkan lukisan sebagai seni secara general, dan yang berikutnya, meletakkan lukisan sebagai salah satu (medium) seni di antara medium seni yang lain. ${ }^{i}$ Secara simplisistik, yang pertama merujuk pada seni rupa modern dan yang kedua pada seni rupa kontemporer.

Pluralitas seni rupa kontemporer, dan terbebasnya seni lukis sebagai paradigma seni rupa menjadikan seni lukis terus hidup dan berkembang dengan berbagai kemungkinan metode dan genre. Pada satu sisi, hal ini semacam pembebasan, namun pada sisi lain juga menyebabkan seni lukis 'terkooptasi' oleh paradigma plural dan cair dari seni rupa kontemporer. Salah satu yang kentara adalah aspek politically correct dalam seni lukis, yang mengutamakan representasi persoalan dari pada persoalan ide dan karakter medium seni lukis - jika istilah kebenaran esetetik dirasakan terlalu parokial. Pada dasarnya dengan keragamannya, seni lukis menjadi bagian penting dalam praktik seni rupa kontemporer global, demikian pula yang tampak dalam seni rupa kontemporer Indonesia. Seni lukis tetap menjadi primadona. 


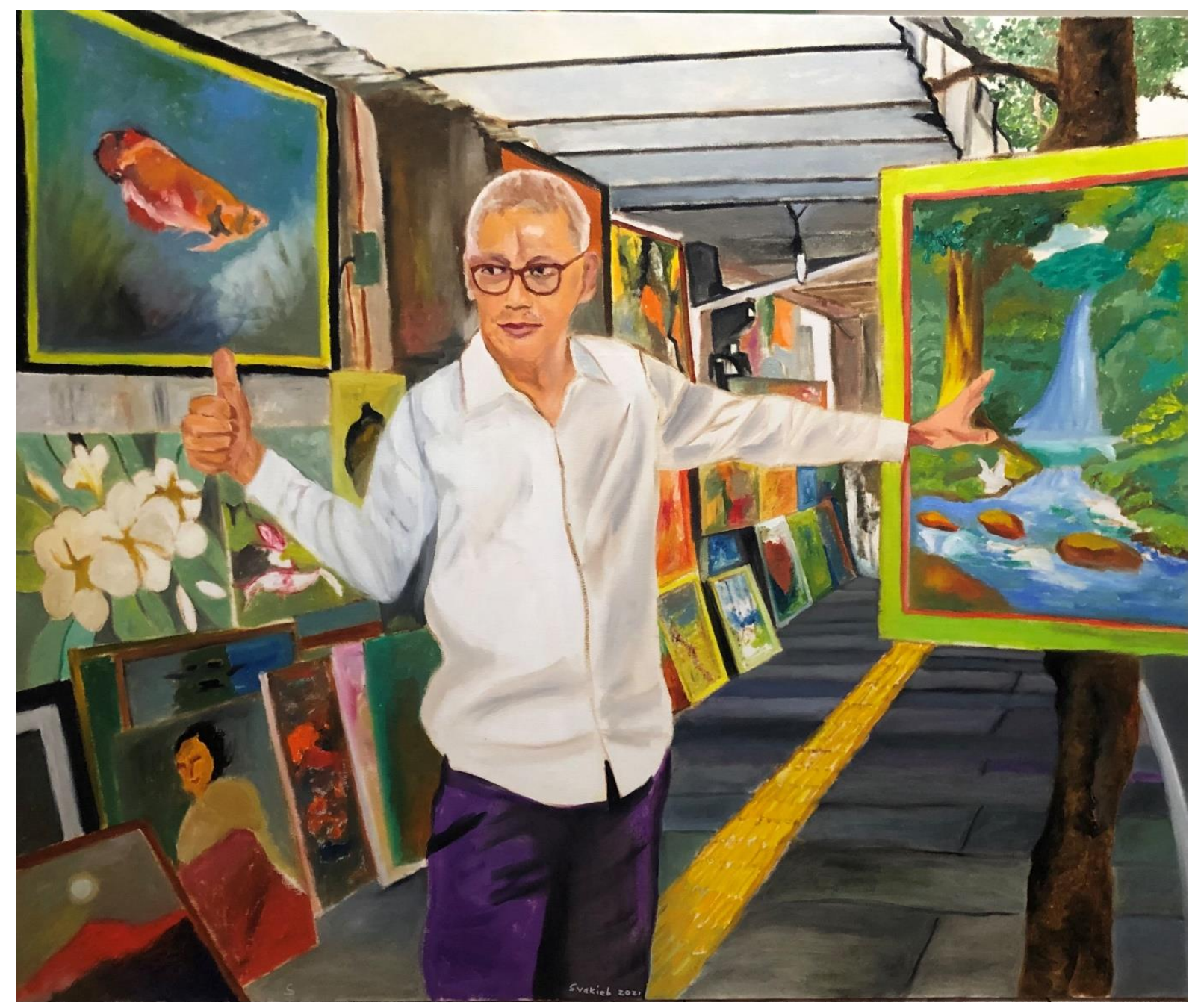

Gambar 4 - Syakieb Sungkar, "Mister Suka Mooi Indie”, 2021.

Beberapa sastrawan dan profesi lain yang masuk ke dalam dunia seni rupa, umumnya akan memilih seni lukis. Mengapa demikian? Sebagaimana telah diutarakan, sejarah seni rupa modern adalah sejarah seni lukis. Dengan kata lain seni lukis menjadi bagian dari ingatan sejarah seni rupa. Dalam konteks seni otonom, kredo ekspresi personal lekat dengan seni lukis. Seni lukis adalah medium yang akomodatif pada jejak seniman (brush stroke dan gestural). Demikian pula, seni lukis adalah medium paling populer dan mudah diterima publik sebagai karya seni, berbeda dengan instalasi, performance atau karya-karya video yang kerap masih mendatangkan kebingungan publik. Pendeknya, seni lukis adalah default mode of art-making. ${ }^{\mathrm{ii}}$ 


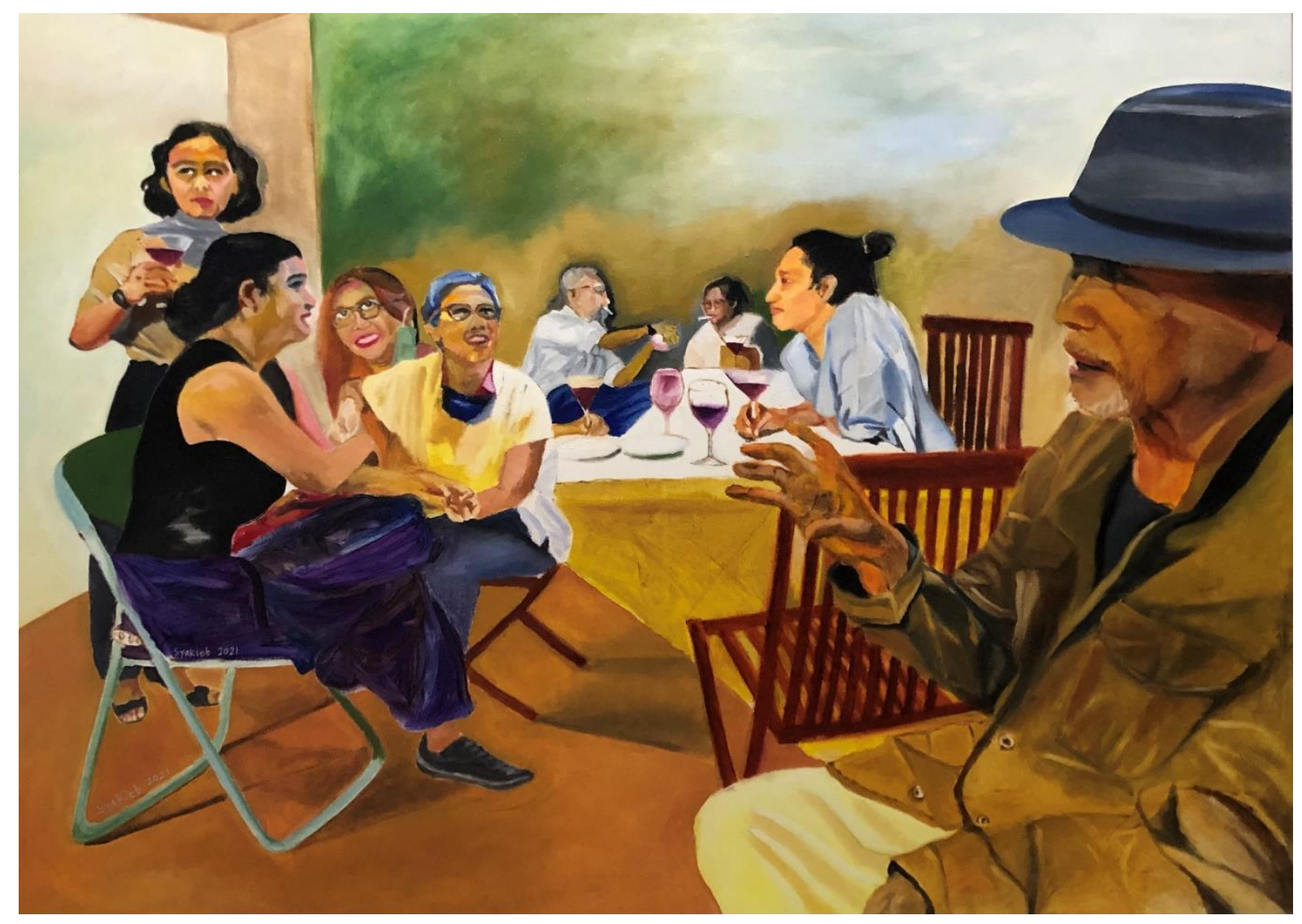

Gambar 5 - Syakieb Sungkar, "Suatu Sore Tanpa Covid”, 2021.

Popularitas seni lukis memang tidak disertai pewacanaan yang cukup intens. Seni lukis kerap dicurigai karena kedekatannya dengan pasar. Pengertian seni lukis sebagai default untuk praktik seni lebih berlaku pada pemahaman publik awam mengenai medium dan praktik seni, bukan pada aspek paradigma seni dan wacana arus utama. Pada aspek wacana, justru seni lukis kerap diaggap sebagai medium yang old fashion. Dalam buku Art Since 1900, Modernism, Antimodernism, Postmodernism, yang dianggap buku babon seni rupa modern dan kontemporer yang ditulis oleh Hal Foster dkk, tinjauan mengenai seni lukis sangat minim. Schwabsky berujar mengenai buku tersebut, setelah Pop Art, capitalist realism dari Gerhard Richter dan Sigmar Polke, “...further developments in painting can be safely ignored.” iii Dalam kekecewaan yang sama terhadap buku tersebut, Tony Godfrey menjelaskan bahwa, “...the chapters dealing with the last three decades of the twentieth century almost totally ignored painting (barely 5 per cent of the images were of painting). Painting had apparently become a mere footnote to the history of contemporary art."iv 


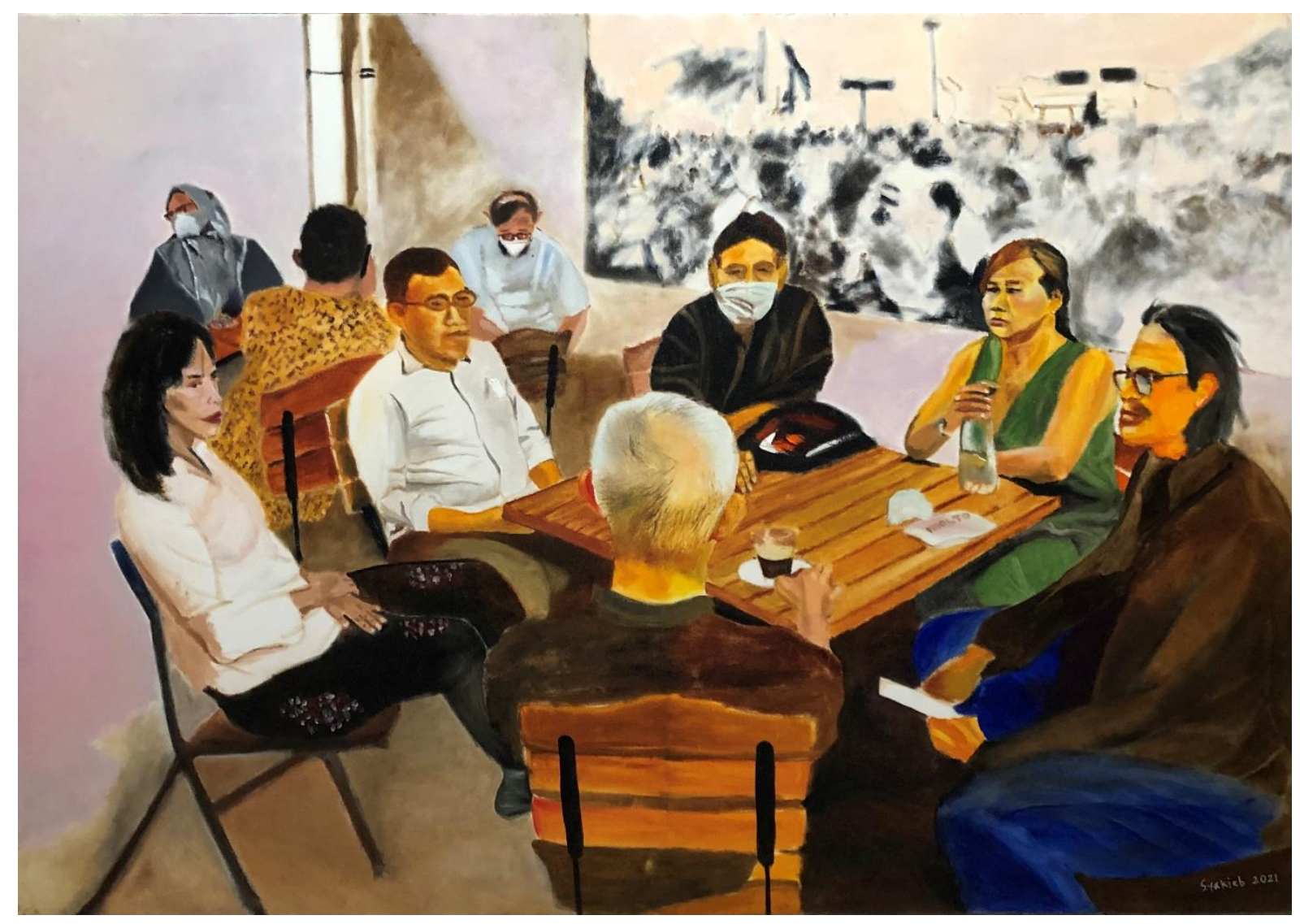

Gambar 6 - Syakieb Sungkar, "Musyawarah Burung”, 2021.

Barry Schwabsky dan Tony Godfrey patut mengutarakan kekecewaannya pada wacana seni rupa kontemporer yang menyingkirkan perbincangan seni lukis kontemporer. Keduanya merupakan pembela seni lukis, dan terlihat dari buku seni lukis yang mereka susun. Namun tidak bisa dipungkiri apa yang tampil dalam buku-buku mereka adalah pluralitas seni lukis kontemporer, dan para pelukis Barat masih tetap mendominasi. Dalam konteks globalisasi, pengaruh Barat menyebar lebih cepat pada praktik seni rupa di luar Barat, baik itu wacana maupun pasar seni rupa, termasuk di Indonesia. Booming seni rupa kontemporer Indonesia tahun 2005 sampai 2009 menunjukkan supremasi seni lukis dengan berbagai genrenya. Saat ini telah lebih dari satu dekade setelah era boom lokal, pasar seni rupa Indonesia masih melempem. Para pelukis masih terus melukis, namun tanpa gairah pasar, tinjauan pada seni lukis - yang sebelumnya pun tak seberapa — saat ini dalam titik rendah. Di masa boom pun tinjuan dan perbincangan pada seni lukis terbatas pada tulisan-tulisan kurasi yang menyertai pameran seni lukis. 


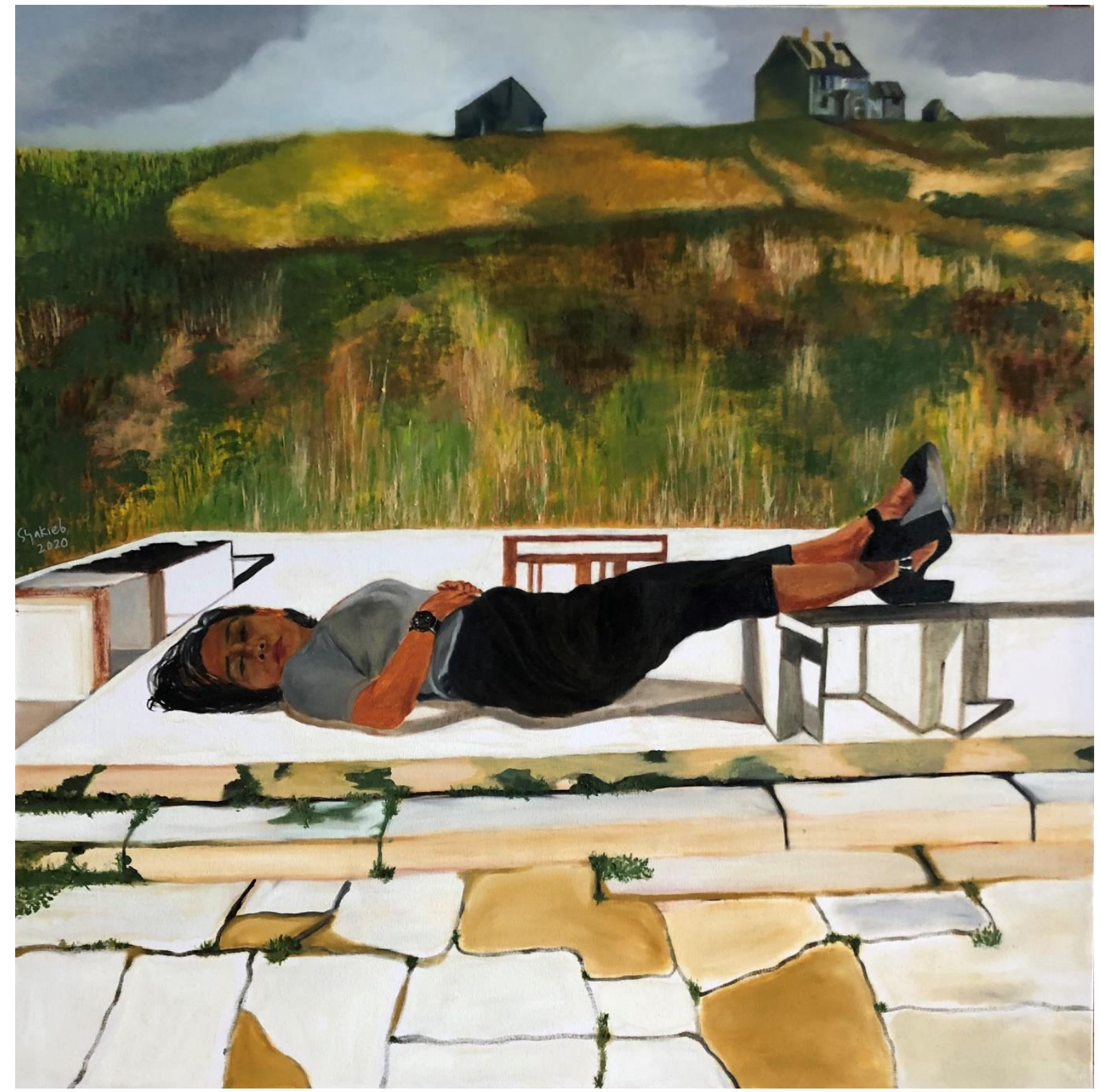

Gambar 7 - Syakieb Sungkar, “Kisah Ening”, 2020.

Dilatari pemahaman pada pluralitas seni lukis — dan siapapun bisa menjadi pelukis/senimandi satu sisi, dan kelesuan pasar seni lukis pada sisi lain, menggerakan Syakieb untuk melukis. Bisa jadi hal ini juga dipicu kerinduannya pada perbincangan mengenai seni lukis. Syakieb faham dalam seni lukis kontemporer perkara gagasan seni lukis dikembalikan pada senimannya. Dalam kaitan ini, sepertinya Syakieb rindu pada lukisan yang menunjukkan karakternya sebagai lukisan, bukan sekadar sebagai wahana representasi persoalan. Bagi Syakieb, metode atau teknik yang dipilih dalam proyeknya untuk menjadi pelukis perlu ditetapkan sejak awal. Bisa diduga hal ini akan berhubungan dengan selera, preferensi artistik 
dan kognisi seni yang dimiliki Syakieb. Hal itu akan menjadi dasar gagasan atau "konsep" lukisannya. Gagasan ini yang menjadi penting yang akan berujung pada karakter visual dari lukisannya. Dengan kata lain lukisan Syakieb merupakan konsekuensi logis dari "proyek seni lukisnya”. Dalam hal ini motif menjadi penting. Motif pelukis modernis dan postmodernis tentu berbeda, atau katakanlah motif pelukis abstrak, realis, atau surealis, masing-masing akan berbeda, dan akan tampak pada lukisannya. Hal itu dijelaskan oleh Barry Schwabsky ketika menjelaskan karya Michael Krebber, seniman German yang karya-karya lukisnya tidak dapat dinilai dari lukisannya semata, karena sang seniman menurut Schwabsky,

"..., the artist has to produce, not so much the work itself (as we'll see, there exist artists whose every effort is to reduce the work to its vanishing points)... But in any case, these minimal attributes of the artwork are so indispensable precisely because they are requisite to any attemp to understand the work's relation to the project that generated it. $^{\mathrm{v}}$

Karenanya aspek ontologis seni lukis menurut Schwabsky terletak bukan pada obyek seninya, melainkan pada artistic enterprise (upaya artistik). Dengan kata lain, aspek ontologis seni lukis dikembalikan pada para pelukisnya sendiri, semacam personal ontologis. Pada era seni rupa kontemporer dengan pluralisme, maka aspek dialektik gaya seni, kredo dan art movement menjadi kurang relevan, karena apapun boleh dilakukan. Karena itu soal "nilai" seni dikembalikan pada kebutuhan masing-masing seniman, termasuk aspek ontologis seni lukis. Saat ini pelukis dapat menempatkan medium lukis sekadar sebagai wahana representasi persoalan (apapun persoalan tersebut), dengan kata lain mengabaikan aspek ontologis atau hakekat seni lukis.

Paradigma seni rupa kontemporer pada dasarnya justru melawan aspek hakekat dalam medium seni, termasuk seni lukis. Karena itu, seni lukis dalam era seni rupa kontemporer justru sangat kaya dengan segala kemungkinan, sebab sang pelukis tidak dibebani oleh tugas mencari esensi seni lukis. Salah satu terbitan mengenai seni lukis kontemporer adalah buku Vitamin P(ainting), yang sudah sampai pada jilidnya yang ketiga. Dalam ketiga buku tersebut, karyakarya para pelukis tidak dikelompokan pada kecenderungan tertentu, namun tersebar secara 
alfabetis di dalamnya. Hal ini menunjukkan bahwa para pelukisnya ditempatkan sebagai entitas personal, yang masing-masing memiliki keistimewaan dan karakternya.

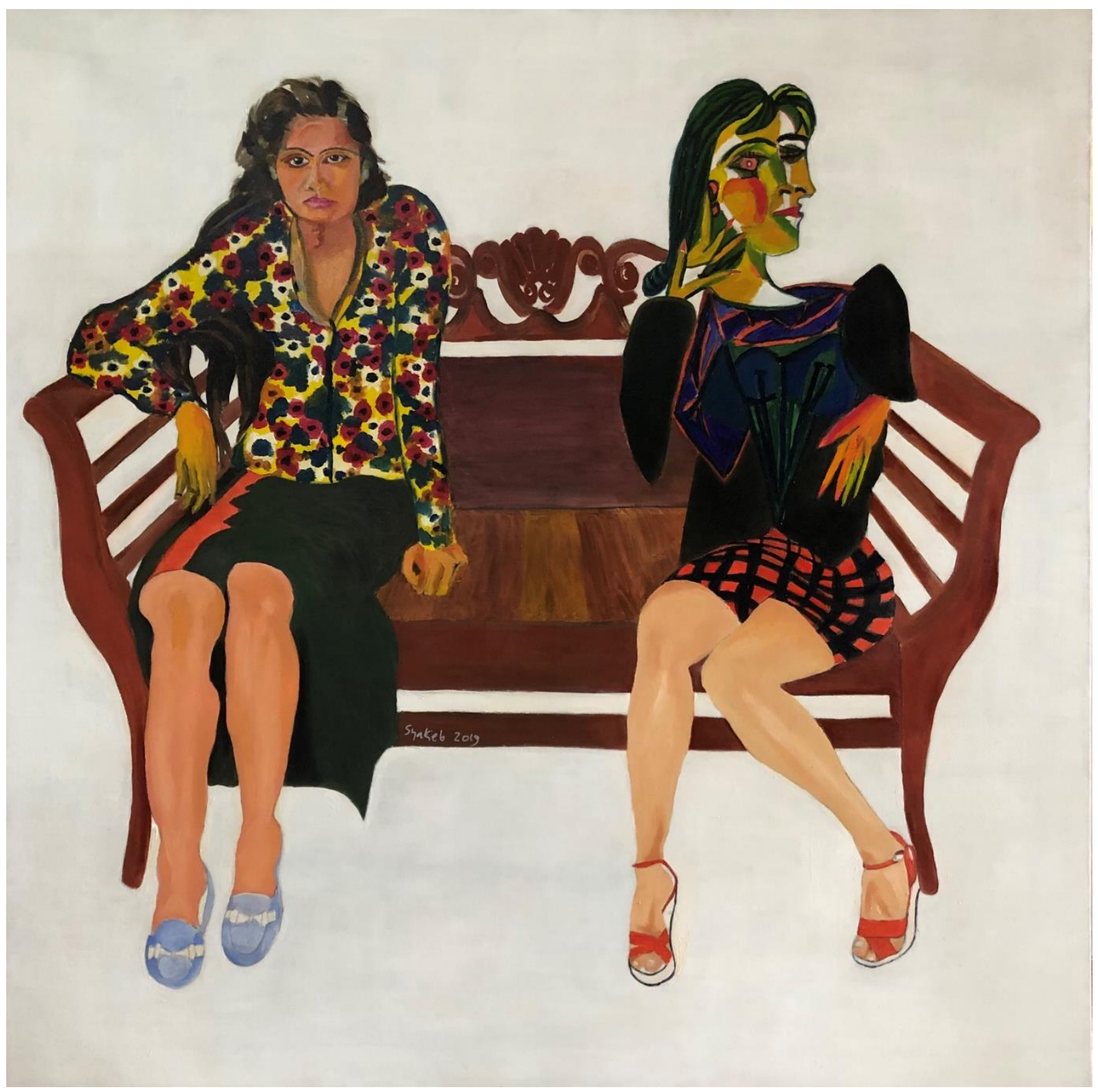

Gambar 8 - Syakieb Sungkar, “Dialog Fatima dengan Dora Maar”, 2019.

Sebagai pelukis baru yang hendak masuk gelanggang seni, mau tidak mau Syakieb harus mempersiapkan diri. Secara tidak langsung, dia mencoba mencari jawaban mengenai motifnya menjadi pelukis, sebagaimana pertanyaan yang diajukan Schwabsky, “...that every arstist's work should stake out a position - that a painting is not only a painting but also representation of an idea about painting. ${ }^{v i}$ Dengan modal cukup trampil menggambar, Syakieb memilih gaya 
realis-ekspresif. Kedua genre tersebut, terutama ekspresionisme merupakan hal penting bagi Syakieb. Karena pada titik tersebut terletak keistimewaan seni lukis. Berbeda dengan mediummedium lain, terutama yang membutuhkan fabrikasi atau karya-karya instalasi dan new media art, yang tidak mebutuhkan sentuhan dan jejak "tangan" seniman, seni lukis sangat kental dengan jejak tangan seniman (brush stroke dan gestural). Kendati pada dasarnya semua karya seni adalah ekspresif, namun medium lukis yang dapat menunjukkan keutamaannya dalam hal ekspresi personal. Norbert Lynton menunjukkan hal tersebut,

"All art is expressive - of its author and of the situation in which he works—but some art in intended to move us through visual gensture that transmit, and perhaps give release to, emotions and emotionally charged massages. Such art is expressionist."vii

Namun, Lynton juga mengingatkan, "But there was never a movement called Expressionism." yang mewadahi aspek naratif dalam lukisannya. Melalui pendekatan Realis-Ekspresif ini Syakieb dapat mendekatkan diri dengan kredo Jiwa Ketok Sudjojono, salah satu pelukis Indonesia yang paling dikaguminya. Bagi Syakieb lukisan-lukisan Sudjojono adalah karya yang dapat menunjukkan ekspresi personal dengan kadar "kebenaran estetik" (aesthetically correct) seni lukis maupun pesan dan representasi yang ditunjukkannya (politically corect), dalam konsteks era tersebut, yang berkait dengan narasi nasionalisme.

Preferensi visual dan teknik melukis Syakieb adalah David Hockney dan Liu Xiaodong. Sesungguhnya kedua pelukis tersebut cukup berbeda latar belakang dan konsep karya lukisnya. David Hockney datang dari generasi pelukis Pop Art Inggris abad lalu. Sedangkan Liu Xiadong adalah pelukis China masa kini yang terkenal, dan dianggap dapat mengembalikan kejayaan seni lukis dengan karakter lukisannya yang painterly. Lukisan-lukisan Hockney tampak dekoratif, komposisional, dan sangat colourful, sedangkan Lukisan-lukisan Xiaodong lebih ekspresif dengan brush stroke yang kuat. Kita dapat merasakan pengaruh kedua pelukis tersebut pada lukisan-lukisan Syakieb. 


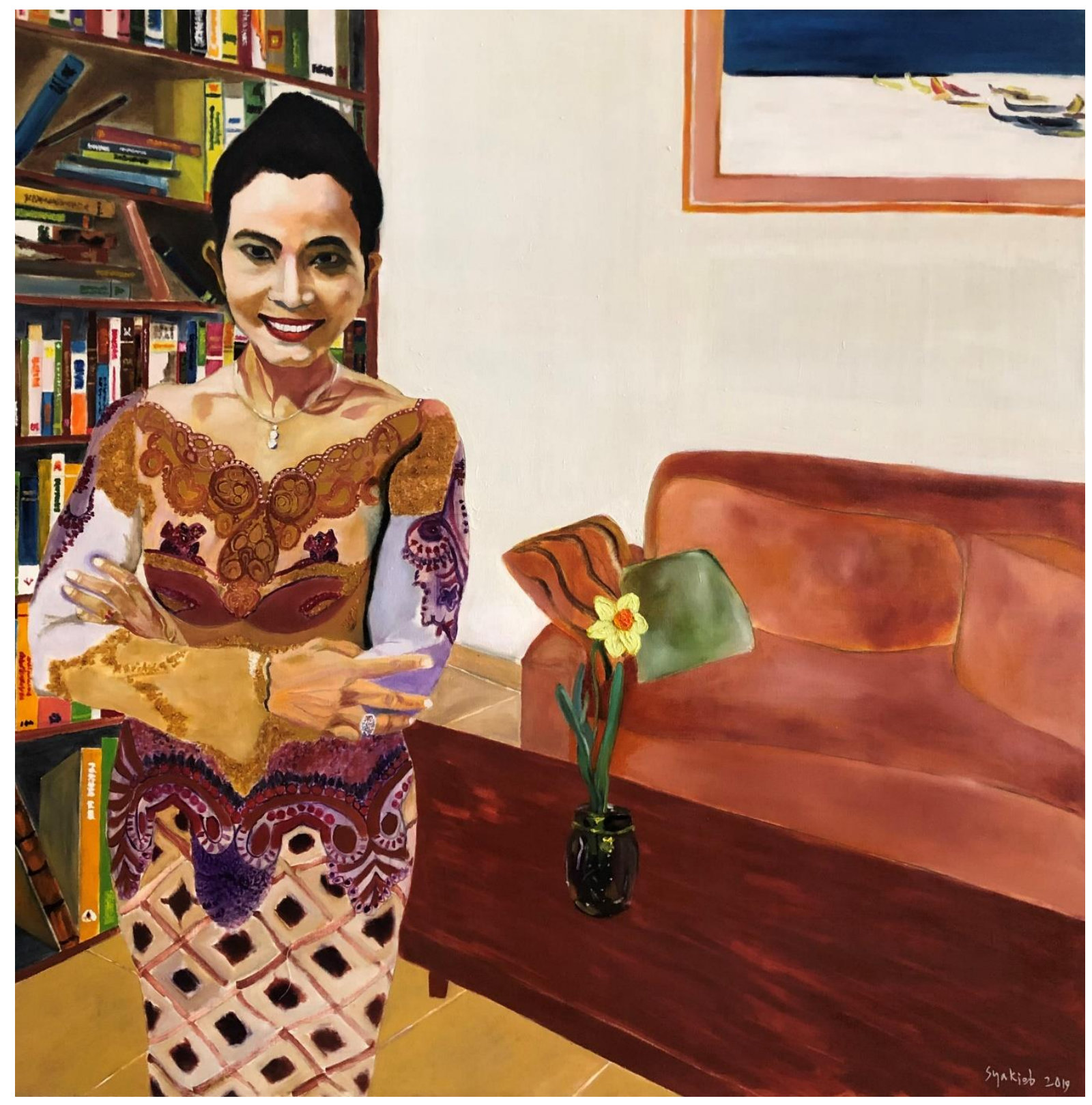

Gambar 9 - Syakieb Sungkar, "Bunga Kuning”, 2019.

Dengan sapuan kuas yang cenderung tidak halus dan blabar nuansa warna yang tidak blended, tampak lukisan-lukisan Syakieb tidak terasa ilusif dengan obyek yang terasa pejal sebagaimana umumnya lukisan foto-realis. Komposisi dalam lukisan Syakieb mengutamakan kedataran (flatness), bukan menekankan ilusi perspektif. Dia juga mempertimbangkan balance, rana dan bangunan warna. Semua itu, ditambah dengan teknik sapuan kuas yang sedikit kasar menjadikan karya Syakieb terasa ekspresif dan painterly. Lukisan tersebut tidak menunjukkan virtusiotas teknik, namun juga sebaliknya tidak dinaif-naif kan. Syakieb cukup cerdas memanfaatkan "keterbatasan" teknis realisnya sebagai jalan masuk untuk menuangkan 
kualitas eskpresif yang painterly. Dalam dominasi genre foto-realis, abstrak, ilustratif/komik/mural, outsider/bad painting dalam peta seni lukis kontemporer Indonesia lukisan-lukisan Syakieb terasa segar sekaligus retro. Memenuhi kerinduan pada lukisan yang tidak pretensius. Lukisan yang memperagakan dirinya sebagai lukisan. Sebagaimana para pioner seni lukis modern Indonesia berkarya lukis.

Berbeda dengan Liu Xiaodong yang lukisannya teatrikal, menampilkan drama dan narasi yang penting serta spektakuler (ukuran lukisannya besar), lukisan-lukisan Syakieb menampilkan narasi sehari-hari, sekitar lingkungannya, orang-orang yang dikenalnya. Kita dapat mengenali beberapa tokoh penting dalam lukisan Syakieb, namun orang-orang tersebut ditampilkan dalam kesehariannya, tidak sebagai model yang duduk (sitter) di depan Syakieb untuk dilukis. Pendekatan ini, dengan narasi sehari-hari makin memperkuat aspek painterly lukisan Syakieb. Sebab lukisan-lukisan tersebut tidak terkooptasi pesan, narasi atau representasinya. Paling jauh, yang kita tangkap adalah humor atau candaan dalam lukisan Syakieb.

Lihat misalnya lukisan dengan judul, "Brokeback Mountain”, "Obral Lukisan”, "Mister Suka Mooi Indie”, "Di Kolam Hockney Kami Berpose”. Bagi yang mengenali person-person dalam medan seni rupa kontemporer tentu dapat membaca candaan Syakieb tersebut. Sementara lukisan "Dinner with Tony", "Musyawarah Burung" dan "Suatu Sore Tanpa Covid" menunjukkan keseharian Syakieb bersama kawan-kawannya. Kita mengenal ada Goenawan Mohamad, Tony Prabowo, Ulil Abshar Abdalla di antaranya. Lukisan-lukisan tersebut tidak menampilkan narasi khusus yang spesifik. Sepertinya subyek matter-atau tepatnya obyekdalam lukisan Syakieb memang hadir sebagai alibi untuk melukis. Bisa jadi untuk Syakieb kejadian yang dilukisnya merupakan hal yang secara personal penting, semacam bagian dari catatan hariannya. Namun untuk permirsa, narasi tersebut tak seberapa penting. Dalam hal ini, bagi Syakieb catatan personal tersebut menambahkan tekanan pada ekspresi personal pada lukisannya, seperti lukisan-lukisan lain dalam pameran ini. Lynton menyebutnya sebagai, "emotionally charged massages". 


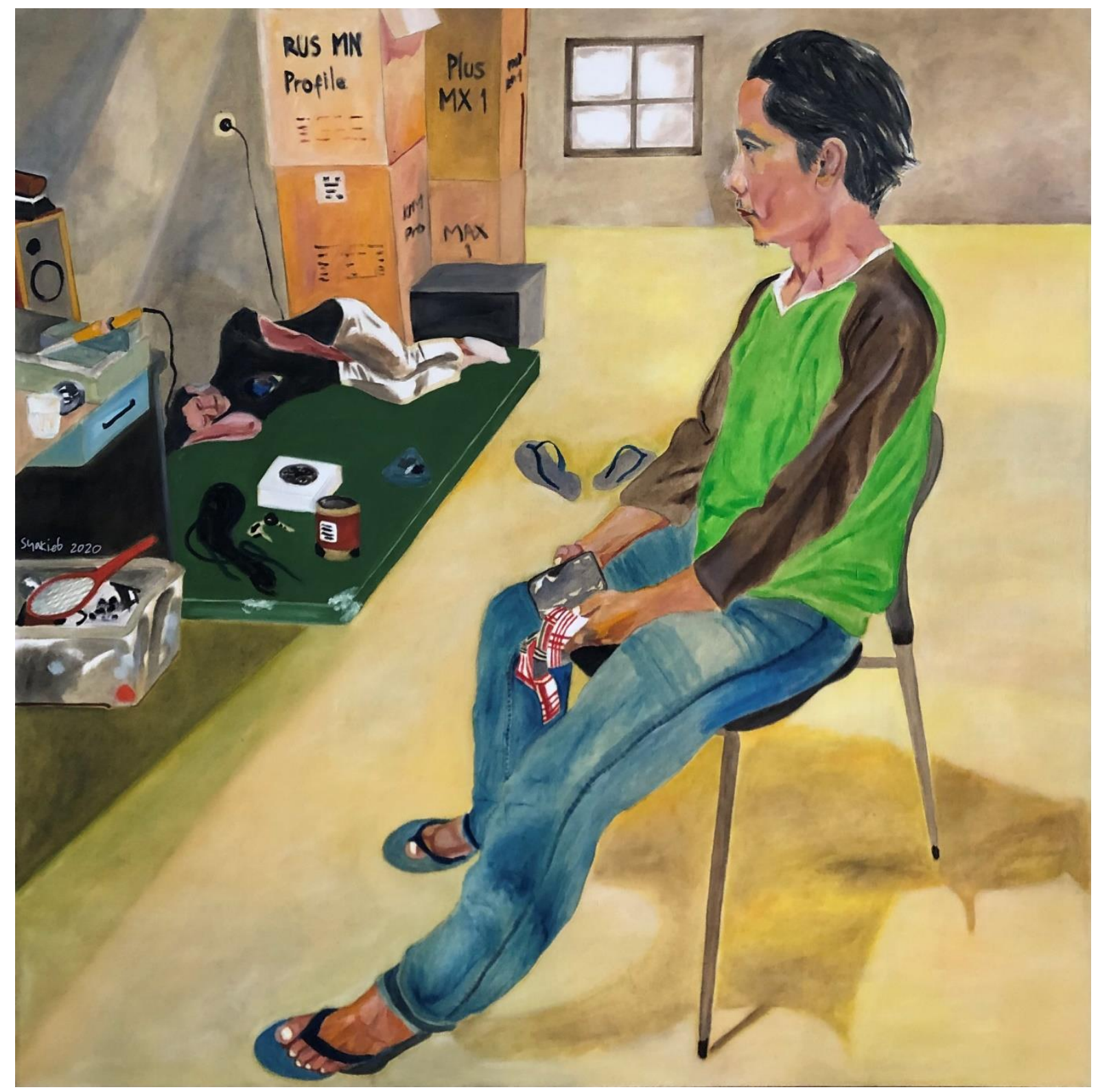

Gambar 10 - Syakieb Sungkar, "Bengkel Salihara”, 2020.

Syakieb tidak mencari kebaruan melalui lukisan-lukisannya_pada saat "apapun boleh" dalam seni rupa kontemporer, kebaruan kerap menjadi superfisial. Dia sekadar ingin mengekspresikan sikap artistiknya melalui proyek lukisannya. Syakieb ingin kembali pada kejujuran atau kekuatan lukisan sebagai lukisan. Salah satu lukisan yang istimewa dalam pameran ini adalah "Dialog Fatima dan Dora Maar", kita tahu sumber dari lukisan tersebut adalah lukisan Sudjojono ("Di Depan Kelambu Terbuka") dan lukisan Picasso ("Portrait of Dora Maar"). Yang menarik, tanpa ragu Syakieb menempatkan wajah Dora Maar dengan gaya kubis, sebagaimana dalam lukisan Picasso dalam lukisan Realisnya. Syakieb tak risau dengan 
"keanehan" lukisan tersebut. Hal ini justru menunjukkan bahwa yang utama bagi Syakieb adalah dia sedang berkarya lukis, tak masalah menabrak genre Realis, toh bukan realita atau perkara rasio yang sedang disampaikannya. Urgensi Syakieb adalah berkesempatan merasakan aksi melukis secara konvensional atau ordinary. Pendekatan ini, tidak banyak lagi dilakukan oleh para pelukis kontemporer Indonesia. Kebanyakan pelukis terjebak pada aspek sensasional seni rupa kontemporer, baik metode maupun kontennya.

Melihat lukisan-lukisan Syakieb, kita merasa de javu. Memang Syakieb menangguk banyak inspirasi dari para pelukis lain yang dikaguminya, yaitu para pelukis yang lukisan-lukisannya kuat menunjukkan "karakter"- untuk tidak menyebut ontologi—seni lukis. Lukisan-lukisan Syakieb memenuhi kualitas yang dijelaskan Schwabsky, "For me, and I think for many other, the ordinariness of painting has become one of its most important characteristics. It's where the much cited modern project of linking art with everyday life continues to be worked out."ix

Bandung, Oktober awal 2021

\footnotetext{
' Barry Schwabsky, Vitamin P, New Perspective in Panting (London: Phaidon Press Limited, 2002), hlm. 5.

ii Barry Schwabsky, Vitamain P2, New Perspective in Painting (London; Phaidon Press Limited, 2011), hlm. 15.

iii Ibid, hlm. 12.

iv Tony Godfrey, Painting Today (London: Phaidon Press Limited, 2009), hlm. 9.

"Barry Schwabsky, “Object or Project? A Critic's Reflection on the Ontology of Painting” dalam Anne Ring Peterson dkk, Contemporary Painting in Context (Copenhagen: Museum Tusculanum Press, 2010), hlm. 73.

vi Barry Schwabsky, Vitamin P, hlm. 7.

vii Norbert Lynton, "Expressionism” dalam Nikos Stangos, ed., Concepts of Modern Art (London: Thames and Hudson, 1981), hlm. 30.

viii Ibid.

ix Barry Schwabsky, Vitamin P2, hlm. 15.
} 